\title{
Prognostic factors in patients with node-negative gastric cancer: an Indian experience
}

Ramakrishnan A Seshadri ${ }^{{ }^{*}}$, Sunil B Jayanand ${ }^{1}$ and Rama Ranganathan ${ }^{2}$

\begin{abstract}
Background: The status of the regional nodes is the most important prognostic factor in gastric cancer. There are subgroups of patients with different prognosis even in node-negative patients of gastric cancer. The aim of this study is to analyze the factors influencing the prognosis in Indian patients with node-negative gastric cancer.

Methods: This was a retrospective analysis of patients who underwent radical gastrectomy in a tertiary cancer centre in India between1991 and 2007. The study group included only patients with histologically node-negative disease. Various clinical, pathological and treatment related factors in this group of patients were analyzed to determine their prognostic ability by univariate and multivariate analyses.

Results: Among the 417 patients who underwent gastrectomy during this period, 122 patients had node-negative disease. A major proportion of the patients had advanced gastric cancer. The 5-year overall survival and diseasefree survival in all node-negative gastric cancer patients was $68.2 \%$ and $67.5 \%$ respectively. The overall recurrence rate in this group was $27.3 \%$. On univariate analysis, the factors found to significantly influence the disease-free survival were the size, location and presence or absence of serosal invasion of the primary tumor. However, on multivariate analysis, only tumor size more than $3 \mathrm{~cm}$ and serosal invasion were found to be independently associated with an inferior survival.
\end{abstract}

Conclusion: Serosal invasion and primary tumor size more than $3 \mathrm{~cm}$ independently predict a poor outcome in patients with node-negative gastric cancer.

\section{Background}

The status of the regional lymph nodes is the most important prognostic factor in gastric cancer and patients with node-negative gastric cancer have a better survival compared to those with nodal metastasis [1,2]. However, even among the node-negative patients, there are certain subgroups of patients who fare better than the others [3-13]. Identification of the poor risk category among the node-negative patients may help in planning adjuvant therapy for this group. Although the incidence of gastric cancer in India is less than other Asian countries like Japan, Korea and China, the age-standardized (world) incidence of gastric cancer in Chennai (12.2 and $6.0 / 100,000$ population in males and females respectively) is among the highest in India [14]. While many previous studies on node-negative gastric cancer have

\footnotetext{
*Correspondence: ram_a_s@yahoo.com

'Department of Surgical Oncology, Cancer Institute (WIA), Chennai-600036, India

Full list of author information is available at the end of the article
}

included a large proportion of patients with early gastric cancer, we wished to study the factors influencing the survival in Indian patients with node-negative gastric cancer, most of whom have advanced gastric cancer. This will help in the optimal utilization of treatment resources for better patient care.

\section{Methods}

We undertook a retrospective analysis of patients diagnosed with gastric cancer who underwent radical gastrectomy with a curative intent in our institution between 1991 and 2007. Prior to 1993, most patients underwent a D1 dissection. From 1993, D2 dissection was the standard treatment for patients with gastric cancer and a D1 dissection was performed only in special situations (patients above 70 years, severely malnourished patients or the occasional patient who underwent emergency surgery for bleeding from the tumor). Only patients in whom routine histological examination (hematoxylin-eosin staining) of the dissected regional 
lymph nodes did not reveal evidence of nodal metastasis were included in the study group. The UICC TNM $6^{\text {th }}$ edition staging system was used for staging the disease [15]. Patients in whom all examined lymph nodes were negative for metastasis regardless of the number of nodes dissected were still designated as $\mathrm{pNO}$ according to the UICC TNM guidelines [15] and were included in the analysis. Patients with carcinoma-in-situ were excluded from the study, since the risk of nodal metastasis is very low in these patients and they cannot be compared with invasive malignancies.

Adjuvant chemotherapy was not administered to any of the patients. The tumors were divided into proximal or distal by an imaginary line between the incisura and the mid-point of the greater curve. The patients were followed 3-monthly for the first three years, 6-monthly for the next two years and then annually thereafter. Clinical examination was performed at each visit and abdominal imaging studies (computerized tomography scan or an ultrasound) was requested every year for the first five years. An endoscopy was performed once a year for three years. Local recurrence identified on endoscopy was always confirmed by a biopsy. Nodal or distant recurrences were identified on imaging and a biopsy was not attempted unless the imaging result was equivocal. The median duration of follow-up of all patients in this study (including 5 patients who had a 30-day mortality) was 58 months (range 1 to 202 months). Univariate analysis of various prognostic factors influencing the disease-free survival (DFS) was performed using log-rank test. Factors identified to be significant in univariate analysis were included in the multivariate analysis, which was performed using the Cox proportional hazard model. The survival estimates were calculated by life-table method. Statistical significance was considered when $p$ value was $<0.05$. The SPSS v11.0.1 software was used for statistical analysis

\section{Results}

Among the 417 patients who underwent radical gastrectomy during the study period, 122 patients had histologically node-negative disease. After excluding one patient with carcinoma-in-situ, the study population had 121 patients (29\%). Table 1 enlists the patient, surgical and pathological details of the node-negative patients. More than $80 \%$ of the patients had advanced gastric cancer (predominantly T3 disease) and D2 lymphadenectomy was performed in $81 \%$ of the patients.

On follow-up, recurrence was detected in 33 patients (27.3\%). Of this, distant metastasis was seen in 24 patients (19.8\%), isolated locoregional recurrence in 6 patients (4.9\%) and combined locoregional and distant recurrence was seen in 3 patients $(2.4 \%)$. The 3 -year and 5 -year overall survival in node-negative patients
Table 1 Clinical, pathological and treatment details of node negative patients

\begin{tabular}{|c|c|}
\hline Variable & No. (\%) \\
\hline \multicolumn{2}{|l|}{ Gender } \\
\hline Male & 86 \\
\hline Female & 35 \\
\hline Median age (range) & 53 years $(27-76)$ \\
\hline \multicolumn{2}{|l|}{ Depth of invasion } \\
\hline pT1 & $22(18.2)$ \\
\hline pT2 & $33(27.3)$ \\
\hline pT3 & $64(52.9)$ \\
\hline pT4 & $2(1.7)$ \\
\hline \multicolumn{2}{|l|}{ Size of primary tumor } \\
\hline$\leq 3 \mathrm{~cm}$ & $18(14.9)$ \\
\hline$>3 \mathrm{~cm}$ & $85(70.2)$ \\
\hline \multicolumn{2}{|l|}{ Grade } \\
\hline 1 & $12(9.9)$ \\
\hline 2 & $39(32)$ \\
\hline 3 & $70(57.9)$ \\
\hline \multicolumn{2}{|l|}{ Histology } \\
\hline Adenocarcinoma & $102(84.3)$ \\
\hline Mucin secreting carcinoma & $13(10.7)$ \\
\hline Signet-ring cell carcinoma & $6(5)$ \\
\hline \multicolumn{2}{|l|}{ Type of gastrectomy } \\
\hline Distal & $97(80.2)$ \\
\hline Total & $21(17.4)$ \\
\hline Proximal & $3(2.5)$ \\
\hline \multicolumn{2}{|l|}{ Extent of lymphadenectomy } \\
\hline D1 & $23(19)$ \\
\hline D2 & $98(81)$ \\
\hline Median no. of dissected nodes (range) & $22(4-77)$ \\
\hline \multicolumn{2}{|l|}{ No. of nodes dissected } \\
\hline$\leq 15$ & $39(32.2)$ \\
\hline$>15$ & $82(67.8)$ \\
\hline
\end{tabular}

were $76 \%$ and $68.2 \%$ respectively, whereas the 3 -year and 5 -year disease-free survival were $73.6 \%$ and $67.5 \%$ respectively. In contrast, the 5 -year overall survival of the 295 patients who had node-positive disease was $29.1 \%$, which was significantly lower than that of nodenegative patients $(p<0.001)$.

On univariate analysis, the only factors which were found to be significantly associated with a poor diseasefree survival in patients with node-negative gastric cancer were tumor size $>3 \mathrm{~cm}$, proximal tumor location and the presence of serosal invasion in the primary tumor (Table 2). The age of the patient, gender, histology and grade of the tumor did not correlate significantly with survival. There was a non-significant trend towards better survival in patients in whom $>15$ nodes were dissected when compared to those with fewer number of dissected nodes. Similarly, although there 
Table 2 Univariate analysis of factors predicting diseasefree survival in node negative gastric cancer

\begin{tabular}{|c|c|c|}
\hline Variable & $\begin{array}{l}\text { 5-year Disease free } \\
\text { survival }\end{array}$ & $p$ value \\
\hline \multicolumn{3}{|l|}{ 1. Gender } \\
\hline Male & $68.2 \%$ & 0.78 (NS) \\
\hline Female & $65.4 \%$ & \\
\hline \multicolumn{3}{|l|}{ 2. Age } \\
\hline$\leq 53$ years & $63.5 \%$ & $\begin{array}{l}0.557 \\
\text { (NS) }\end{array}$ \\
\hline$>53$ years & $71.5 \%$ & \\
\hline \multicolumn{3}{|l|}{ 3. Haemoglobin } \\
\hline$\leq 9 \mathrm{gm} \%$ & $59.03 \%$ & 0.42 (NS) \\
\hline$>9 \mathrm{gm} \%$ & $70.6 \%$ & \\
\hline \multicolumn{3}{|l|}{ 4. Patient Weight } \\
\hline$\leq 50 \mathrm{~kg}$ & $68.7 \%$ & 0.44 (NS) \\
\hline$>50 \mathrm{~kg}$ & $66.5 \%$ & \\
\hline \multicolumn{3}{|l|}{ 5. Location of tumor } \\
\hline Distal & $71.8 \%$ & 0.05 \\
\hline Proximal & $48.6 \%$ & \\
\hline \multicolumn{3}{|l|}{ 6. Multi-organ resection } \\
\hline None & $68.2 \%$ & 0.69 (NS) \\
\hline Pancreaticosplenectomy & $55.4 \%$ & \\
\hline Others & $100 \%$ & \\
\hline \multicolumn{3}{|l|}{ 7. Dissection } \\
\hline D1 & $53.5 \%$ & $\begin{array}{l}0.100 \\
\text { (NS) }\end{array}$ \\
\hline D2 & $70.1 \%$ & \\
\hline \multicolumn{3}{|l|}{ 8. Histology } \\
\hline Adenocarcinoma & $65.5 \%$ & 0.30 (NS) \\
\hline Mucinous carcinoma & $84.6 \%$ & \\
\hline $\begin{array}{l}\text { Signet ring cell } \\
\text { carcinoma }\end{array}$ & $62.5 \%$ & \\
\hline \multicolumn{3}{|l|}{ 9. Grade } \\
\hline 1 & $80 \%$ & $0.14(\mathrm{NS})$ \\
\hline 2 & $76.8 \%$ & \\
\hline 3 & $60 \%$ & \\
\hline \multicolumn{3}{|l|}{ 10. Tumor size } \\
\hline$\leq 3 \mathrm{~cm}$ & $94.3 \%$ & 0.003 \\
\hline$>3 \mathrm{~cm}$ & $55.9 \%$ & \\
\hline \multicolumn{3}{|l|}{ 11. Serosal invasion } \\
\hline Absent & $86.4 \%$ & 0.0002 \\
\hline Present & $51.9 \%$ & \\
\hline \multicolumn{3}{|l|}{ 12. No of nodes dissected } \\
\hline$\leq 15$ & $59.6 \%$ & 0.07 (NS) \\
\hline$>15$ & $71.3 \%$ & \\
\hline \multicolumn{3}{|l|}{ 13. Gastric outlet obstruction } \\
\hline Absent & $70.3 \%$ & $0.27(\mathrm{NS})$ \\
\hline Present & $60.7 \%$ & \\
\hline \multicolumn{3}{|l|}{ 14. Blood loss } \\
\hline$\leq 400 \mathrm{ml}$ & $72.9 \%$ & $0.17(\mathrm{NS})$ \\
\hline$>400 \mathrm{ml}$ & $64.3 \%$ & \\
\hline
\end{tabular}

NS- not significant. was a trend towards improved survival in patients undergoing D2 lymphadenectomy when compared to D1, we could not demonstrate any statistical significance. On multivariate analysis, only the primary tumor size $>3 \mathrm{~cm}$ and presence of serosal invasion were found to be independently associated with an inferior diseasefree survival (Table 3). The survival curves in patients with node-negative gastric cancers according to tumor size and serosal invasion are presented in Figures 1 and 2 respectively.

\section{Discussion}

The status of regional nodes is the most important prognostic factor in gastric cancer [1,2]. Node-negative patients have a significantly better survival when compared to node-positive patients. The 5-year and 10-year overall survival in node-negative patients have been reported to vary from $72 \%$ to $91.7 \%$ [2-10] and $88 \%$ to $93 \%[3,6,11]$ respectively. The recurrence rates vary from $13.7 \%$ to $29.4 \%$ in this favorable subset of patients $[7,8,10,12]$. Most of these series come from East Asian countries and include a sizeable proportion of early gastric cancer. Our series, which reflects the Indian scenario, has a majority of patients diagnosed with advanced gastric cancer and hence the 5-year survival rates reported by us $(68.2 \%)$ is slightly less than that quoted in the literature. However, in one of the largest series, comprising more than 1500 patients with node negative gastric cancer, Kim et al [13] reported a comparable 5-year survival (66.9\%) in patients with advanced gastric cancer.

The proportion of node-negative patients in our study, although less than that reported from many East Asian countries $[5,11,13]$, is comparable to that reported in some western centers $[4,9]$. There are two reasons for this. First, aggressive screening programmes, as practiced

Table 3 Multivariate analysis of prognostic factors in node negative gastric cancer

\begin{tabular}{|c|c|c|c|}
\hline Variable & $\begin{array}{l}\text { Hazard } \\
\text { ratio }\end{array}$ & $\begin{array}{l}95 \% \text { confidence } \\
\text { interval }\end{array}$ & $\begin{array}{l}p \\
\text { value }\end{array}$ \\
\hline \multicolumn{4}{|l|}{$\begin{array}{l}\text { 1. Location of } \\
\text { tumor }\end{array}$} \\
\hline Distal & $1^{*}$ & & \\
\hline Proximal & 1.43 & $0.73-2.79$ & $\begin{array}{l}0.36 \\
(\mathrm{NS}) \\
\end{array}$ \\
\hline \multicolumn{4}{|l|}{ 2. Tumor size } \\
\hline$\leq 3 \mathrm{~cm}$ & $1^{*}$ & & \\
\hline$>3 \mathrm{~cm}$ & 7.97 & $1.08-59.06$ & 0.04 \\
\hline \multicolumn{4}{|c|}{ 3. Serosal invasion } \\
\hline Absent & $1^{*}$ & & \\
\hline Present & 2.13 & $1.04-4.35$ & 0.04 \\
\hline
\end{tabular}

*Reference value NS- not significant. 


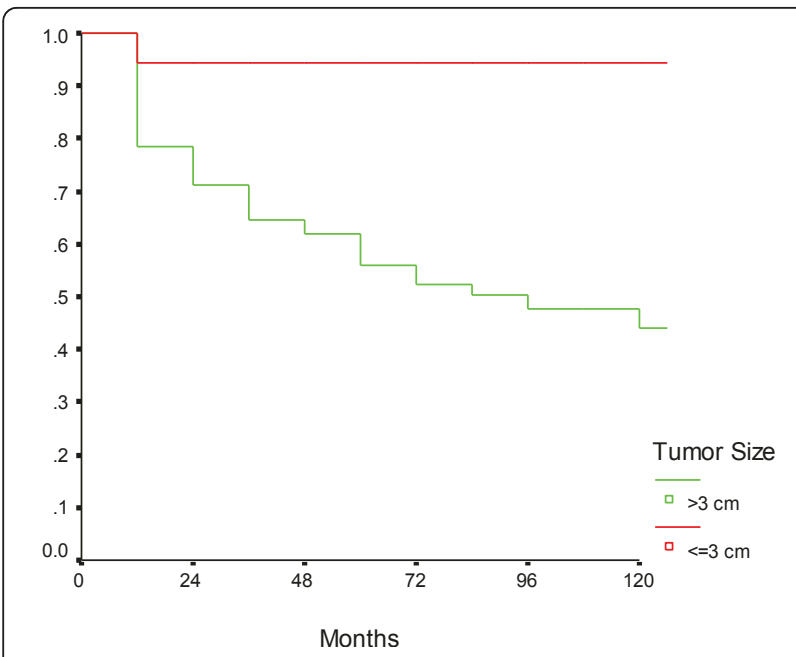

Figure 1 Survival in node negative gastric cancer patients according to tumor size. The disease-free survival of patients with tumor size $\leq 3 \mathrm{~cm}$ was higher than that of patients with tumors size $>3 \mathrm{~cm}$.

in Japan leads to early detection of gastric cancer whereas in India, many patients present in an advanced stage due to the lack of such screening programmes. Second, it has been observed that node-negative gastric cancer is frequently associated with small tumor size (usually $<4 \mathrm{~cm}$ ) $[3,5,11]$, less poorly differentiated tumors [3] and are usually confined to the muscularis propria $[3,11]$. In the entire population of 417 gastric cancer patients treated in our institution, the mean size of the primary tumor was $5.3 \mathrm{~cm}, 69 \%$ of the patients had high grade tumors and $75 \%$ of the patients had disease extending beyond the muscularis propria (data not shown) - all of which

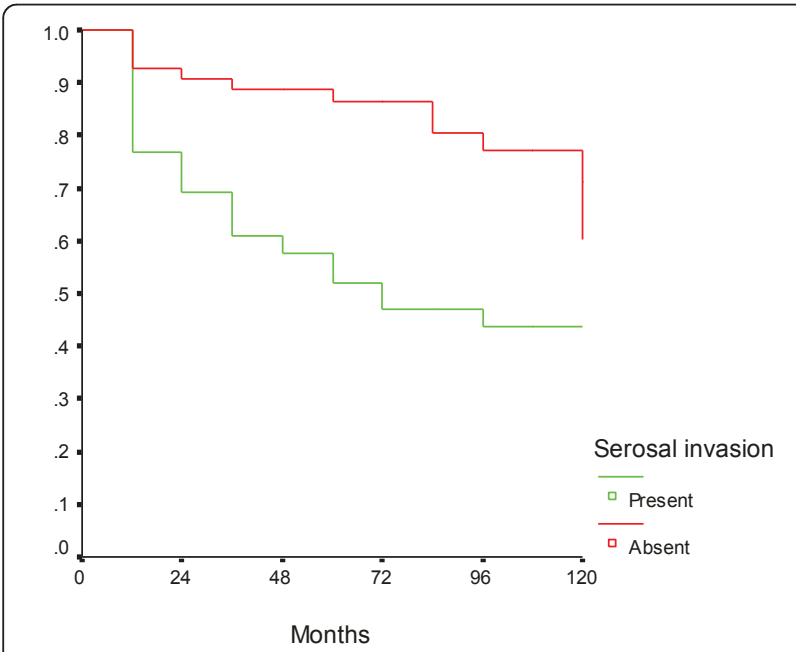

Figure 2 Survival in node negative gastric cancer patients according to serosal invasion. The disease-free survival of patients with serosal invasion was lower than that of patients without serosal invasion. probably account for a high proportion of nodal metastasis among Indian patients.

Various clinico-pathological factors have been reported to influence the survival and recurrence rates in node-negative gastric cancer. The size of the primary tumor has been reported to be a significant prognostic factor for survival in earlier studies $[5,6,10,13,16]$, and has been confirmed in our study as well. The presence of serosal invasion, which emerged as an independent prognostic factor in our study has been documented by other authors $[4,8,10,12,13,16]$. The depth of invasion of the primary tumor has also been reported as a prognostic factor [3,11,17-19]. Proximal location of the tumor was significant only on univariate analysis in our study, but lost significance on multivariate analysis. Similarly, distal tumor location did not emerge as an independent prognostic factor in other studies $[3,19]$. In contrast, Deng et al. [8] found that patients who underwent subtotal gastrectomy had a significantly longer median overall survival when compared to those who underwent a total gastrectomy (116 vs 91 months, $\mathrm{p}=0.03$ ), which indirectly reflected the influence of tumor location on survival. Lauren's histological classification has been reported to be an independent prognostic factor in node-negative gastric cancer, with the intestinal type having a better prognosis than the diffuse type $[12,19]$. Even though we did not use the Lauren's classification in our study, the histological subtype of the tumor according to the WHO classification did not emerge as a significant prognostic factor in our analysis. The other factors which have been found to influence survival in patients with node-negative gastric cancer include presence of lympho-vascular invasion $[3,12,16,18,20]$, age $[11,17,18,21]$, gender [8], vascular invasion $[5,22]$, Sphase fraction [23] and proliferating cell nuclear antigen (PCNA) labeling index [24]. Poorly differentiated tumors also have a poor prognosis $[4,10]$, although in our analysis we were not able to demonstrate a significant association between the histological grade of the tumor (which denotes the tumor differentiation) and survival.

Extended lymphadenectomy has been reported to be an independent prognostic factor for survival in nodenegative gastric cancer by few authors $[6,21,25]$ whereas others have reported that this survival benefit is limited only to patients withT3 disease $[9,17]$. It is recommended that a minimum of 15 nodes be dissected for proper staging in gastric cancer [15]. The number of node to be dissected in patients with node-negative gastric cancer is unclear, although Giuliani et al recommended examination of at least 23 nodes in these patients for identifying prognostic indicators [26]. Huang et al. [7] found that the number of dissected lymph nodes was an independent prognostic factor for survival in patients with node-negative gastric cancer 
and that there was a negative correlation between the number of dissected nodes and recurrence rates. By cutpoint analysis, these authors reported better survival in pT1-2 patients in whom $\geq 15$ nodes were dissected, in pT3-4 patients in whom $\geq 20$ nodes were dissected and in the entire group of patients if $\geq 15$ nodes were dissected. In a retrospective analysis, Biffi et al reported that the disease-free and overall survival of node-negative gastric cancer patients was significantly improved when at least 15 nodes were dissected regardless of the $\mathrm{pT}$ stage and that the risk of distant metastasis decreased with increase in the number of dissected nodes [27]. Shen et al. [28] reported that there was a positive association between the number of nodes dissected and the chance of identifying nodal metastasis in pT3 but not pT1 or pT2 gastric cancer $(\mathrm{HR}=1.014$, 95\% CI 1.006-1.021). However, they failed to demonstrate an independent prognostic value of the number of nodes dissected in pT3N0 patients. In another study [8], it was observed that patients in whom more than 20 nodes were dissected had a longer median disease-free survival than patients in whom fewer than 20 nodes were dissected ( 47.5 versus 21.4 months, $\mathrm{p}=0.01$ ). In our study, although there was a definite trend towards better survival in patients who underwent D2 dissection and in patients in whom $>15$ nodes were examined, we were not able to demonstrate a statistically significant association between these factors and patient survival. This is probably due to the small sample size.

The benefit of extended lymphadenectomy seems to be due to the eradication of potential micrometastatic disease [7]. Using reverse transcription polymerase chain reaction assay, Wu et al. [29] detected micrometastasis in $20 \%$ of patients who were determined to be node negative on routine hematoxylin-eosin stains. Immunohistochemical studies have also been used to detect micrometastasis in $10-32 \%$ patients with gastric cancer [30-33]. The presence of micrometastasis significantly impacts the prognosis of patients with node-negative gastric cancer. Patients who do not harbour micrometastasis have been found to have a significantly better survival than those who harbour micrometastasis in the nodes [29,31-35]. The type of micrometastasis also seems to have an impact on the outcome. Yasuda et al. observed that patients with $\geq 4$ micrometastasis have a significantly worse outcome when compared to those with fewer micrometastasis and also that those with micrometastasis in extragastric nodes fare poorly [32]. In another study, Cao et al reported that the clustertype micrometastasis had a significantly poor survival when compared to the single-cell type micrometastasis [31]. The presence of micrometastasis in the nodes has been correlated with loss of E-cadherin expression in the primary tumor as well as the size, depth of invasion and differentiation of the primary tumor [30-35]. It is interesting to note that most of the variables are themselves independent prognostic factors in node-negative gastric cancer, and therefore, their prognostic importance may be attributed to the presence of micrometastasis. Thus, identifying micrometastasis in node-negative gastric cancer patients may help in prognostication as well as determining the need for adjuvant therapy.

The prognostic value of adjuvant therapy in node-negative gastric cancer has not been reported in the English literature. Adjuvant chemotherapy has been shown to improve the survival in gastric cancer in general $[36,37]$. However, it is difficult to say whether adjuvant chemotherapy will add to the already favourable prognosis of nodenegative gastric cancer. This can be answered only by a multicenter randomized trial of adjuvant chemotherapy exclusively in patients with node-negative gastric cancer.

\section{Conclusion}

Although patients with node-negative gastric cancers had a favorable survival in our study, the subgroup of patients with a tumor size more than $3 \mathrm{~cm}$ or tumors invading the serosa had a worse prognosis when compared to those having smaller tumors or those without serosal invasion. The low rate of locoregional recurrence in our study may be related to the extended nodal dissection performed in most patients. An attempt should be made in all node-negative patients to identify lymph node micrometastasis since it may further help in prognostication. The available evidence from literature suggests that an extended lymphadenectomy with dissection of at least 15 nodes must be performed even in patients with clinically negative nodes. However, surgical treatment alone is unlikely to prevent distant recurrences, even in nodenegative gastric cancer. Hence, systemic therapy may have a role in node-negative gastric cancer patients. In a country like India, where it is essential to utilize the available treatment resources judiciously, patients with nodenegative gastric cancer with a tumor $>3 \mathrm{~cm}$ or invading the serosa or with lymph node micrometastasis should be considered for more aggressive adjuvant therapy in the form of systemic chemotherapy.

\section{Acknowledgements}

We wish to acknowledge the immense help rendered by Mr. Sivakumar M and Mrs. Lakshmi Dhanasekar in retrieving the case records and updating the patient follow-up status.

\section{Author details}

'Department of Surgical Oncology, Cancer Institute (WIA), Chennai-600036, India. ${ }^{2}$ Department of Biostatistics and Tumor Registry, Cancer Institute (WIA), Chennai-600036, India.

\section{Authors' contributions}

RAS was involved in the conception and design of the study, extraction of data, interpretation of data, literature search and critical appraisal and 
revision of the manuscript. SBJ was involved in extraction of data, statistical analysis, literature search and writing the first draft of the manuscript. RR was involved in statistical analysis, interpretation of data and review of the manuscript. All authors read and approved the final manuscript.

\section{Competing interests}

The authors declare that they have no competing interests.

Received: 20 January 2011 Accepted: 10 May 2011

Published: 10 May 2011

\section{References}

1. Siewert JR, Bottcher K, Stein HJ, Roder JD: Relevant prognostic facors in gastric cancer: Ten year results of the German Gastric Cancer Study. Ann Surg 1998, 228:449-461.

2. Kim JP, Lee JH, Kim SJ, Yu HJ, Yang HK: Clinicopathologic characteristics and prognostic factors in 10783 patients with gastric cancer. Gastric Cancer 1998, 1:125-133.

3. Lee CC, Wu CW, Lo SS, Chen JH, Li AF, Hsieh MC, Shen KH, Lui WY: Survival predictors in patients with node-negative gastric carcinoma. J Gastroenterol Hepatol 2007, 22:1014-1018.

4. Bruno L, Nesi G, Montinaro F, Carassale G, Boddi V, Bechi P, Cortesini C: Clinicopathologic characteristics and outcome indicators in nodenegative gastric cancer. J Surg Oncol 2000, 74:30-32.

5. Yokota T, Kunii Y, Teshima S, Yamada Y, Saito T, Takahashi M, Kikuchi S, Yamauchi H: Significant prognostic factors in patients with nodenegative gastric cancer. Int Surg 1999, 84:331-336.

6. Maehara Y, Tomoda M, Tomisaki S, Ohmori M, Baba H, Akazawa K, Sugimachi K: Surgical treatment and outcome for node-negative gastric cancer. Surgery 1997, 121:633-639.

7. Huang CM, Lin JX, Zheng CH, Li P, Xie JW, Lin BJ, Lu HS: Prognostic impact of dissected lymph node counts on patients with node-negative gastric cancer. World J Gastroenterol 2009, 15:3926-3930.

8. Deng J, Liang H, Sun D, Zhang R, Zhan H, Wang X: Prognosis of gastric cancer patients with node-negative metastasis following curative resection: Outcomes of the survival and recurrence. Can J Gastroenterol 2008, 22:835-839.

9. Harrison LE, Karpeh MS, Brennan MF: Extended lymphadenectomy is associated with a survival benefit for node-negative gastric cancer. $J$ Gastrointest Surg 1998, 2:126-131.

10. Saito H, Kuroda H, Matsunaga T, Fukuda K, Tatebe S, Tsujitani S, Ikeguchi M: Prognostic indicators in node-negative advanced gastric cancer patients. I Surg Oncol 2010, 101:622-625.

11. Adachi Y, Mori M, Maehara Y, Kitano S, Sugimachi K: Prognostic factors of node-negative gastric carcinoma: univariate and multivariate analyses. J Am Coll Surg 1997, 184:373-377.

12. Huang KH, Chen JH, Wu CW, Lo SS, Hsieh MC, Li AF, Lui WY: Factors affecting recurrence in node-negative advanced gastric cancer. J Gastroenterol Hepatol 2009, 24:1522-1526.

13. Kim DY, Seo KW, Joo JK, Park YK, Ryu SY, Kim HR, Kim YJ, Kim SK: Prognostic factors in patients with node-negative gastric carcinoma: A comparison with node-positive gastric carcinoma. World J Gastroenterol 2006, 12:1182-1186.

14. Curado MP, Edwards B, Shin HR, Storm H, Ferlay J, Heanue M, Boyle P, (Eds): Cancer Incidence in five continents Volume IX. IARC scientific publication No.160 Lyon, France: IARC Press; 2007.

15. Sobin LH, Wittekind Ch, (Eds): International Union Against Cancer (UICC): TNM Classification of malignant tumours. 6 edition. Wiley: New York; 2002.

16. Qui MZ, Wang ZQ, Zhang DS, Zhou ZW, Li YH, Jiang WQ, Xu RH: Prognostic analysis in node-negative gastric cancer patients in China. Tumor Biol 2010.

17. Park SS, Park JM, Kim JH, Kim WB, Lee J, Kim SJ, Kim CS, Mok YJ: Prognostic factors for patients with node-negative gastric cancer: Can extended lymph node dissection have a survival benefit? J Surg Oncol 2006, 94:16-20

18. Ichikawa D, Kubota T, Kikuchi S, Fujiwara H, Konishi H, Tsujiura M, Ikoma H, Nakanishi M, Okamoto K, Sakakura C, Ochiai T, Kokuba Y, Otsuji E: Prognostic impact of lymphatic invasion in patients with node-negative gastric cancer. J Surg Oncol 2009, 100:111-114.

19. Baiocchi GL, Tiberio GA, Minicozzi AM, Morgagni P, Marrelli D, Bruno L, Rosa F, Marchet A, Coniglio A, Saragoni L, Veltri M, PAcelli F, Roviello F, Nitti D, Giulini SM, De Manzoni G: A multicentric western analysis of prognostic factors in advanced, node-negative gastric cancer patients. Ann Surg 2010, 252:70-73.

20. Lee JH, Choi SH, Min JS, Noh SH: Prognostic impact of lymphatic and/or blood vessel invasion in patients with node negative advanced gastric cancer. Ann Surg Oncol 2002, 9:562-567.

21. Baba H, Maehara Y, Takeuchi H, Inutsuka S, Akazawa K, Sugimachi K: Effect of lymph node dissection on the prognosis in patients with nodenegative early gastric cancer. Surgery 1995, 117:165-169.

22. Kooby DA, Suriawinata A, Klimstra DA, Brennan MF, Karpeh MS: Biologic predictors of survival in node-negative gastric cancer. Ann Surg 2003, 237:828-837.

23. Cascinu S, Graziano F, Catalano V, Valentini M, Rossi MC, Baldelli AM, Ghiselli R, Saba V, Giordani P, Catalano G: Prognostic value of S-phase fraction in T3NOMO gastric cancer. Implications for adjuvant chemotherapy. Anticancer Res 2000, 20:3839-3842.

24. Maehara Y, Kabashima A, Tokunaga E, Hasuda S, Oki E, Kakeji Y, Baba H, Sugimachi K: Recurrences and relation to tumor growth potential and local immune response in node-negative advanced gastric cancer. Oncology 1999, 56:322-327.

25. Otsuji E, Kuriu Y, Ichikawa D, Ochiai T, Okamoto K, Hagiwara A, Yamagishi H: Efficacy of prophylactic extended lymphadenectomy with gastrectomy for patients with node-negative advanced gastric carcinoma. Hepatogastroenterology 2008, 55:755-759.

26. Giuliani A, Caporale A, Corona M, Di Bari M, Demoro M, Ricciardulli T, Gozzo P, Galati G, Tocchi A: Lymphadenectomy in gastric cancer: influence on prognosis of lymph node count. J Exp Clin Cancer Res 2004, 23:215-224.

27. Biffi R, Botteri E, Cenciarelli S, Luca F, Pozzi S, Valvo M, Sonzogni A, Chiappa A, LealGhezzi T, Rotmensz N, Bagnardi V, Andreoni B: Impact on survival of the number of lymph nodes removed in patients with nodenegative gastric cancer submitted to extended lymph node dissection. Eur J Surg Oncol 2011, 37:305-11.

28. Shen JY, Kim S, Cheong JH, Kim Yl, Hyung WJ, Choi WH, Choi SH, Wang LB, Noh SH: The impact of total retrieved lymph nodes on staging and survival of patients with pT3 gastric cancer. Cancer 2007, 110:745-751.

29. Wu ZY, Li JH, Zhan WH, He YL, Wan J: Effect of lymph node micrometastases on prognosis of gastric carcinoma. World I Gastroenterol 2007, 13:4122-4125.

30. Kim JJ, Song KY, Hur H, Hur Jl, Park SM, Park CH: Lymph node micrometastasis in node negative early gastric cancer. Eur J Surg Oncol 2009, 35:409-414.

31. Cao L, Hu X, Zhang Y, Huang G: Adverse prognosis of clustered-cell versus single-cell micrometastases in pNO early gastric cancer. J Surg Oncol 2011, 103:53-56.

32. Yasuda K, Adachi $Y$, Shiraishi N, Inomata M, Takeuchi H, Kitano S: Prognostic effect of lymphnode micrometastasis in patients with histologically node-negative gastric cancer. Ann Surg Oncol 2002, 9:771-774.

33. Lee E, Chae Y, Kim I, Choi J, Yeom B, Leong AS: Prognostic relevance of immunohistochemically detected lymphnode micrometastasis in patients with gastric carcinoma. Cancer 2002, 94:2867-2873.

34. Kim JH, Park JM, Jung CW, Park SS, Kim SJ, Mok YJ, Kim CS, Chae YS, Bae JW: The significance of lymphnode micrometastasis and its correlation with E-cadherin expression in PT1-T3N0 gastric adenocarcinoma. J Surg Oncol 2008, 97:125-130.

35. Cai J, Ikeguchi M, Tsujitani S, Maeta M, Liu J, Kaibara N: Significant correlation between micrometastasis in the lymph nodes and reduced expression of E-cadherin in early gastric cancer. Gastric Cancer 2001, 4:66-74.

36. Sakuramoto S, Sasako M, Yamaguchi T, Kinoshita T, Fujii M, Nashimoto A, Furukawa H, Nakajima T, Ohashi Y, Imamura H, Higashino M, Yamamura Y, Kurita A, Arai K, for the ACTS-GC group: Adjuvant chemotherapy for gastric cancer with S-1, an oral fluoropyrimidine. N Eng J Med 2007, 357:1810-1820

37. Paoletti X, Oba K, Burzykowski T, Michiels S, Ohashi Y, Pignon JP, Rougier P, Sakamoto J, Sargent D, Sasako M, Van Cutsem E, Buyse M, GASTRIC (Global Advanced/Adjuvant Stomach Tumor Research International Collaboration) Group: Benefit of adjuvant chemotherapy for resectable gastric cancer: a meta-analysis. JAMA 2010, 303:1729-1737.

doi:10.1186/1477-7819-9-48

Cite this article as: Seshadri et al:: Prognostic factors in patients with node-negative gastric cancer: an Indian experience. World Journal of Surgical Oncology 2011 9:48. 